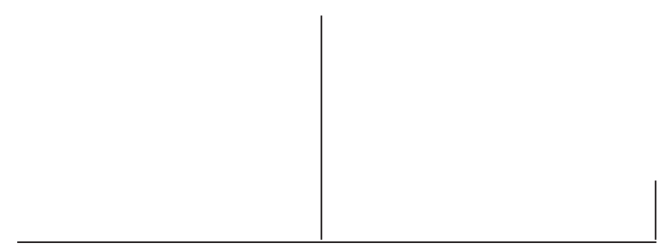

Rev. Latinoam. Psicopat. Fund., IX, 3, 423-432

\title{
A ambivalência como problemática particular no debate entre psicanálise e política*
}

Paulo César Endo

Este trabalho problematiza a dicotomia indivíduo e sociedade no debate social e político contemporâneos, grifando o papel da psicanálise nesse debate e sua presença crescente no pensamento político nas últimas décadas. Destaca o diálogo do pensamento social contemporâneo com o pensamento freudiano no reposicionamento de questões epistemológicas centrais em torno do tema indivíduo/ sociedade, e sinaliza alguns avanços possíveis nessa empreitada em torno da discussão sobre ambivalência.

Palavras-chave: Psicanálise, política, indivíduo, sociedade, ambivalência

* Este trabalho foi originalmente apresentado no VII Congresso Brasileiro de Psicopatologia Fundamental, realizado na PUC-RJ em setembro de 2004. Agradeço aos colegas Pablo, Bruno, Carlo, Martha, Eduardo, René e Márcia, colegas do CEBRAP, por nosso programa de discussões e debates sobre o pensamento político moderno e contemporâneo que ajudaram a esclarecer alguns pontos subjacentes deste trabalho. 


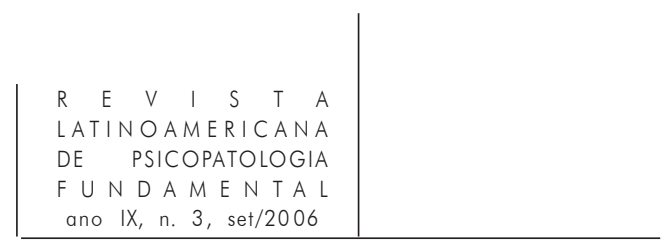

Em 1939, Norbert Elias escreve um artigo intitulado "A sociedade dos indivíduos”. Esse texto deveria servir como introdução à sua grande obra "O processo civilizador" publicada nesse mesmo ano, considerada por alguns uma das obras mais importantes do século XX. ${ }^{1}$

Por opção do autor a introdução não foi publicada, o que só virá a ocorrer em 1987. No ano seguinte (1988) o livro A sociedade dos indivíduos ganha o prêmio Amalfi, concedido ao melhor livro europeu publicado em ciências sociais.

O problema central do artigo formula uma crítica sobre tradição do pensamento social do final do século XIX até o início do século XX (Spengler, Durkheim, Le Bon) que, a partir da dicotomia indivíduo/ sociedade, colocara a questão da singularidade e das formações sociais no campo dos problemas insolúveis.

Nessa tradição do pensamento social, o indivíduo nada mais é do que uma parte, um pedaço da sociedade e a sociedade nada mais é do que a “coexistência aditiva de indivíduos”. E toda a articulação possível entre fenômenos individuais e sociais termina aí. Essa formulação tem bastado para que se desista de investigar as tensões dinâmicas e processos que dizem respeito aos indivíduos em sociedade ou, como quer Elias, "A sociedade dos indivíduos". Indivíduo e sociedade perdurariam como conceitos que se definem reciprocamente, com extrema docilidade, sem que haja, entre eles, qualquer tensão.

Sabemos que os problemas sociais não se reduzem aos problemas individuais e vice-versa. “... a consciência que temos de nós próprios enquanto sociedade e a outra enquanto indivíduos nunca encaixam completamente uma na outra” dirá Elias (1939, p. 24).

1. Ver a introdução à edição brasileira de Renato Janine Ribeiro para o "Processo civilizador" volume I de Norbert Elias. 
O campo de problemas que Elias aponta em 1939, já estava sendo elaborado por Freud desde 1908 com "A moral sexual 'cultural' e a nervosidade moderna”. Argumento que será radicalizado em "Totem e tabu”. É nessa obra de Freud que vários autores contemporâneos (Enzensberger, 1991; Agamben, 1995; Girard, 1972) reconheceram a pedra de toque que contribuiu para alterar decisivamente os debates sobre política, introduzindo de forma radical e inequívoca o problema da ambivalência na ação política.

A contribuição de Freud é, do mesmo modo, diversas vezes convocada nas reflexões de Elias. Seja observando a força da "regulação dos impulsos" a partir da "sólida formação do superego" que torna mais "penoso" o "processo civilizacional individual” ou quando grifa o risco de que "o equilíbrio entre as tendências pessoais e tarefas sociais constituir algo que se situe fora do alcance do ser humano singular" (Elias, 1939, p. 48). Isso que se encontra devidamente delineado desde 1908 e, a partir daí, em todos os chamados textos sociais de Freud, constrói o argumento que aponta o sujeito moderno como capaz de colocar a corda em seu próprio pescoço, impondo-se exigências que não é capaz de cumprir.

O que não está em Freud é a convicção de que "a saciação da fome do ego e do superego" opera na "gênese das tensões sociais" na medida em que essas tensões implicam novas "diferenciações das funções sociais" que, por sua vez, interatuam dando guarida e produzindo novas "funções psíquicas" (ibid., p. 64). Elias descreve e assinala um circuito que produz e é produzido no seio das tensões inerentes à insuficiência e ao mal-estar, que definem a contigüidade presente entre indivíduo e sociedade.

Parece evidente, no entanto, que o problema assinalado por Elias, já discutido paralelamente por Freud diversas vezes, e particularmente em suas elaborações sobre o fenômeno social e político $(1913,1920,1921,1930)$, se coaduna à crítica nascente aos fundamentos do pensamento social do século XIX que, ao fazer uso do procedimento dicotômico, conduz as reflexões em torno do indivíduo e da sociedade a uma espécie de insolvência que evita, a todo custo, reconhecer e aprofundar o problema da ambivalência nas dinâmicas e tensões indivíduo/ sociedade.

O recurso permanente de Elias aos conceitos de id, ego e superego, não deixa dúvidas sobre a concordância do autor com as proposições de Freud após 1923, mas acrescenta também que é nesse interjogo de tensões, representado pelas instâncias psíquicas, que se elabora a gênese do sintoma que torna possível ao indivíduo representar-se como interioridade absoluta, capaz de encerrar-se em si mesmo recebendo, a posteriori, as emanações do exterior, da sociedade.

A partir de Freud, Elias apresenta o problema das antinomias e/ou dicotomias (indivíduo/sociedade) como um sintoma social que atravessa o indivíduo, a 


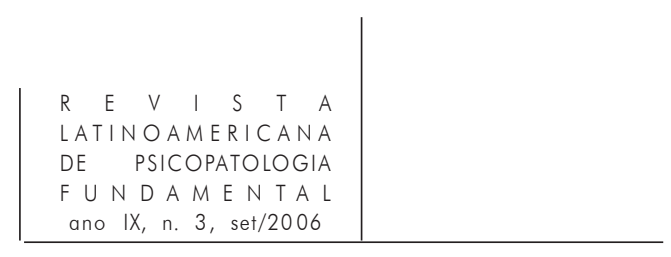

sociedade e o saber que ela produz. Reconhece aí, no pensamento freudiano, a chave para a compreensão dessa fratura interpretando-a, justamente, como um sintoma, ou como, em seus próprios termos, uma "modelação histórica do interior anímico em si” (Elias, 1939, p. 76).

Trata-se de procurar uma passagem menos problemática entre processos sociais e políticos e o problema da singularidade. Nesse sentido, sua posição é clara: "A psicologia constitui, resumindo, a ponte entre as ciências naturais e as ciências naturais" (ibid., p. 60). A psicologia à qual Elias recorre é a metapsicologia, e a ponte entre a natureza e a cultura, o indivíduo e a sociedade é o psiquismo. Sua perspectiva é, entretanto, ligeiramente invertida: "Deve-se, pelo contrário, começar pela respectiva estrutura das relações entre os indivíduos, a fim de se poder compreender a estrututura da 'psique' do homem singular" (ibid., p. 68).

A inversão metodológica sugerida por Elias não impõe graves conseqüências para a metapsicologia, ${ }^{2}$ mas aponta para a dissolução de certos problemas do pensamento social que se encontrariam em elaboração na psicanálise freudiana.

As noções de "fome de ego" e "fome de superego" indicam, em Elias, uma similitude em relação com as necessidades orgânicas (fome) ao mesmo tempo em que se diferencia completamente dela. Ou seja, são necessidades tão imperativas quanto as necessidades orgânicas, mas constituídas na "gênese das tensões sociais" onde se diferenciam as funções sociais e psíquicas. É o exame dessas tensões que pode pôr à mostra os nexos entre desejos e necessidades sociais e os processos de singularização que lhes são correspondentes.

Nas palavras de Elias:

É concretamente a monopolização de bens e valores que serve à saciação da "fome" do ego e do superego; são precisamente estas que, para além da monopolização das que servem à saciação da fome pura, para a gênese das tensões sociais assumem uma importância cada vez maior conforme a diferenciação das funções sociais e com ela também a das funções psíquicas vai aumentando, quanto mais o nível de vida normal de uma sociedade ultrapassar

2. Em determinadas passagens do texto de Elias é possível, e necessário, destacar certos posicionamentos bastante frágeis em seu manejo do conceitual psicanalítico. Quando aponta que "mesmo na literatura psicanalítica deparamos por vezes com afirmações que exprimem aproximadamente a idéia de 'id’ ou dos impulsos serem imutáveis, não contando com a mudança na direção dos impulsos.” (1939, p. 54).Tal afirmação resulta quase ingênua quando remetida à teoria freudiana das pulsões em alguns dos textos fundamentais de Freud (1915). Mas também contradiz as próprias reflexões de Elias em torno das noções de "fome do ego" e do "superego" ao longo de seu próprio texto discutido aqui. 
a da satisfação das mais elementares necessidades alimentares e sexuais (Ibid., p. 64)

A sociedade se complexifica no mesmo torvelinho onde as funções psíquicas se diferenciam gerando novas posições subjetivas e outras e novas formações sociais. É o que vemos representado na imagem/conceito proposta por Elias: a teia de funções. Onde as partes que configuram o todo só são visíveis em seu ponto de partida, para depois se dissolverem no todo constituído pela teia e por suas funções, necessárias para a manutenção de sua arquitetura tensional.

As partes que se ligam perfazem uma história de ligação que coincide com a história singular do indivíduo, seus lugares de passagem, que não podem ser, de modo algum, produzidos individualmente, isto é, fora da teia.

A segunda tópica, nas mãos de Elias, torna-se a face exposta da singularidade, contígua às emanações do social, igualmente emanando em direção ao social que se constitui como teia, totalidade exposta ao tempo e remetida à sua própria funcionalidade como fator que a faz perdurar ou romper-se.

Anos mais tarde veremos Adorno (1956) retomando a questão ao problematizar as noções de indivíduo, sociedade, grupos e massas. Sua crítica incide, do mesmo modo, sobre uma tradição do pensamento social que se esforça para negligenciar o papel do indivíduo - ou da singularidade - ao mesmo tempo em que se esfalfa para atravessar as zonas críticas onde se constituem sujeitos e produções singulares que interferem decisivamente nas formações e processos sociais.

É isso, sem dúvida, que levou Adorno a observar que "o conceito de sociedade define mais as relações entre os elementos componentes e as leis subjacentes nessas relações do que, propriamente, os elementos e suas descrições comuns” (1956, p. 26). A definição de sociedade se degenera quando pretende elidir as diferenças e as singularidades, desse modo, torna-se inócua como idéia homogeneizadora e inibidora das tensões que lhe são inerentes em sua gênese contínua e interminável.

Ao contrário, tratar-se-ia de constituir modos de interpretação dinâmicos e competentes para capturar os movimentos sociais no seio das produções dos sujeitos e entre sujeitos. No que tange à dicotomia indivíduo/sociedade, seu exame crítico permitiria entrever, naquilo que delimita esses dois campos, a tensão e a ambivalência que lhe são inerentes e que foi encabulada pela solução dicotômica.

O paradoxo, Adorno o apontou. Trata-se de reconhecer que "mesmo antes de ser indivíduo o homem é um semelhante...” (ibid., p. 47), ou seja, mesmo antes de se auto-reconhecer, o sujeito é reconhecido numa base onde não lhe é dado, a princípio, diferir. Sua caracterização é sua condenação: este, que acaba de nascer, é um semelhante. 


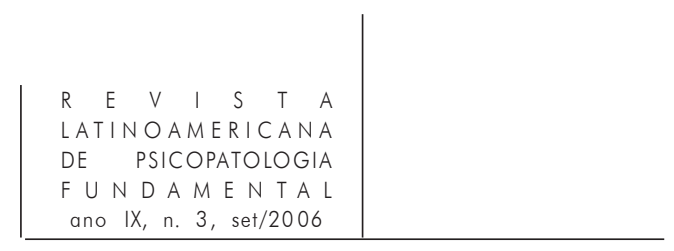

Estar entre outros, como condição previamente determinada, é o que instaura a tensão e o mal-estar. Tensão e mal-estar que penetra no campo dos saberes e que pretende repousar em dicotomias insuficientes e obtusas. Ao reconhecer isso, desde o princípio, a psicanálise aponta o imenso e inexorável risco de existir a partir do desejo de outrem. Mal-estar original que define previamente nossa própria existência no seio de uma história que nos é alheia. A origem do sujeito singular repousa, desde o princípio, nos narcisismos de outrem.

Essa outridade constitutiva é dramatizada nos dilemas indivíduo e sociedade onde se criam armadilhas conceituais que, sob o aspecto da integração, fazem desaparecer, completamente, a idéia de singularidade. A esse propósito, Norbert Elias, direta ou indiretamente, chamou a atenção para determinadas teorizações da psicologia social que recriavam conceitos como alma coletiva (Le Bon), Jung (inconsciente coletivo), complexos de massa etc., ${ }^{3}$ pretendendo transpor conceitos extraídos da psicologia individual para formações sociais. Psicologização que, pretendendo integrar campos distintos, terminavam por fazer desaparecer a idéia da singularidade em nome de um sujeito médio que representaria a sociedade e suas manifestações (cf. Elias, 1939, p. 24). São essas as abordagens mais próximas das tipologias, dos procedimentos estatísticos em busca de sujeito social normal, que resultam no apagamento radical da idéia de sujeito, pondo fim, por essa via, às tensões entre indivíduo e sociedade.

A crítica incisiva desses pensadores sociais, com evidente vocação interdisciplinar, atravessou toda a segunda metade do século XX. De mãos dadas com o pensamento freudiano vemo-la revigorada na produção do pensamento político contemporâneo. Não se trata, de modo algum, de um diálogo esporádico, rarefeito, que só pode ser resgatado a peneiradas e tem vertigem a grandes altitudes. Ao contrário, podemos reconhecê-los em algumas das contribuições fundamentais do pensamento político e social contemporâneo.

Precisamente nesse sentido é que Giorgio Agamben (1995), comentando "Totem e tabu" diz: "Todavia é somente com este livro que uma genuína teoria geral da ambivalência vem à luz sobre bases não apenas antropológicas e psicológicas, mas também lingüísticas” ( p. 86).

A tese central do livro de Agamben, o desvendamento do Homo Sacer como figura paradigmática da derrocada das democracias na contemporaneidade, da

3. Freud também recaiu nessa tentação quando fala de um "superego da cultura”, embora, em se tratando da psicanálise freudiana, essas "criações" ou perderam o efeito ou serviram, tal como o uso de analogias, para elucidar uma passagem especialmente difícil nas elaborações freudianas. Isso acabava por assinalar, ou grifar, um problema deixado em suspenso nas teorizações de Freud. Ver Endo, Paulo (2005), segunda parte. 


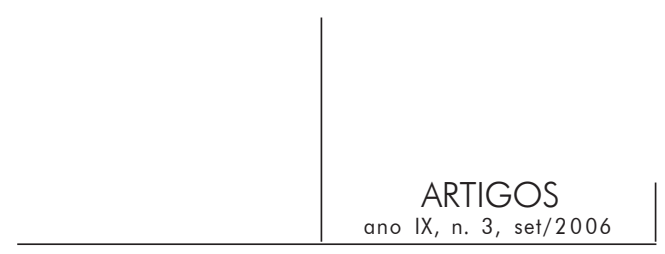

insuficiência das normas como instrumento civilizador e da exposição do corpo, do homem matável como palco privilegiado onde se exerce a exceção é, em parte, atribuída ao texto de Freud "Totem e tabu”.

Mas Agamben destaca que uma genuína teoria da ambivalência vem à luz em “Totem e tabu”, não apenas sobre bases psicológicas e antropológicas, mas também lingüísticas. A ambivalência do termo Sacer que significa tanto santo quanto maldito, foi destacada por Agamben como figura do direito romano arcaico, aplicada a determinados indivíduos que eram, por definição, matáveis, porém insacrificáveis. Ou seja, podiam ser mortos sem que qualquer punição recaísse sobre seu algoz, mas não podiam ser sacrificados em oferenda aos deuses. Eram indignos para tanto, já que teriam sido ofertados, desde a origem, aos deuses ínferos, deuses inferiores.

Agamben assinala a presença da ambigüidade do termo Sacer em várias ocasiões na obra de Freud (1910, 1913, 1915-1917, 1938, 1939). A preocupação de Freud, em todos os casos, é demonstrar a ambivalência presente nas palavras antigas que comportavam, de algum modo, a mesma propriedade encontrada nos sonhos: o descaso para com o princípio da contradição e dos contrários.

Em “Moisés e o monosteísmo”, porém, Freud associa a ambigüidade do termo Sacer (sacro) - santo e maldito - à figura egrégia do pai (sagrada) que é ao mesmo tempo detestável e maldita devido às penosas renúncias pulsionais que exige. O que fica evidente já em 1913 quando Freud comenta a propósito da horda fraterna: “... odiavam o pai que tão violentamente se opunha à sua necessidade de poder e a suas exigências sexuais, porém, ao mesmo tempo o amavam e admiravam...” (p. 1.839).

A investigação freudiana sobre a ambivalência é transportada, de modo consistente e esclarecedor, para as elaborações de Agamben sobre o poder do rei e do tirano. Rei e tirano como forma dicotômica da monarquia que tanto pode desdobrar-se numa república quanto numa tirania. Todavia, a figura do pai como fundamento do poder do monarca é, tanto para Freud quanto para Agamben, a figura originária e ambivalente do poder. Amado e detestado, sagrado e maldito, isto é, sacer.

Voltamos então ao problema das dicotomias reconhecendo-as como instrumento de triunfo sobre a ambivalência, de triunfo sobre o onírico, da superação de todo caos pela ordem. As dicotomias como instrumentos da dominação e do poder, cujo ideal é a univocidade de sentido e a literalidade semântica.

As dicotomias operam instrumentadas pela violência, e a insuflam, no sentido em que postulam, por intermédio das suas operações, o fim da contingência, do latente, do imprevisível e do estranho. 


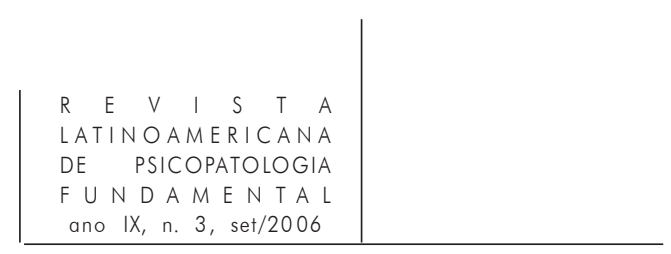

Aquele que não é amigo, nem inimigo, é estranho insiste Bauman (1991). O estranho é a figura contemporânea do matável, daquele que não pode, e não deve, ser assimilado de nenhum modo e, como tal, colocado fora do ponto onde denuncia o fracasso do ordenamento. Nos porões da pólis, nos espaços mais internos da cidade, onde não são vistos, não por estarem para fora dos muros da pólis, mas por estarem excessivamente perto, guardados para serem arbitrariamente invadidos, violados.

Os vulneráveis, excluídos, desiguais, periféricos, marginais que se tornaram os matáveis (ou condenados) das cidades, como quer Wacquant (1991), não são a forma negativa da dicotomia, mas a forma ambivalente, estranha ante a qual as dicotomias já fracassaram. Eles representam os que não se sabe muito bem o que fazer com eles. Como sobra, resto, subproduto não reciclável. São acumulados, amontoados, massificados como forma homogênea, sem singularidades, nem diferenças. E serão, por obra da violência, reduzidos ao que é mau, ruim, sujo e, repetidamente, condenados por isso.

A ambivalência, se não pode ser vivida, suportada, é detestada.

“A ambivalência é o limite do poder dos poderosos" grifa Bauman (1991, p. 190), reconhecendo no pensamento freudiano um dos pilares do pensamento moderno que, entretanto, se opõe aos abusos da racionalidade moderna. Ao postular uma interpretação sem fim, análises intermináveis, Freud executaria, para Bauman, a um só golpe o ordenamento, como forma final de apaziguamento subjetivo, e a tirania que imediatamente se sucederia a partir de uma determinada ordem vitoriosa, frente à qual todos deveriam curvar-se.

O tabu como atualização da proibição e da transgressão assinala que a própria ineficácia das leis, reside no esquecimento de seus fundamentos. Assinala também que o assassinato do pai, obra de uma coletividade, instaurou a lei que nos defenderia de nós mesmos, desde que, ao aplicá-la, rememorássemos o sangue fresco que ainda escorre em nossas mãos.

A leitura dicotômica dos processos coletivos sempre nos levará de volta ao abrigo onde a pureza perdura à custa da imolação dos impuros.

\section{Referências}

Adorno, Theodor (1956). Temas básicos de sociologia. São Paulo: Cultrix/Edusp, 1986. Agamben, Giorgio (1995). Homo Sacer: o poder soberano e a vida nua. Belo Horizonte: UFMG, 2002.

Bauman, Zygmunt (1991). Modernidade e ambivalência. Rio de Janeiro: Jorge Zahar, 1999. 
Elias, Norbert (1939). A sociedade dos indivíduos. Lisboa: Publicações Dom Quixote, 1993.

Endo, Paulo Cesar. A violência no coração da cidade: um estudo psicanalítico sobre as violências na cidade de São Paulo. São Paulo: Escuta/Fapesp, 2005.

Enzensberger, Hans Magnus. Reflexões diante de uma vitrine. Revista USP, São Paulo: Edusp, n. 9, p. 9-22, mar.-abr.-maio/1991.

FreUd, Sigmund (1908). La moral sexual “cultural” y la nerviosidad moderna. In: Obras Completas. Madrid: Biblioteca Nueva, 1981. t. II, p. 1249-61.

(1910). El doble sentido antitético de las palabras primitivas. In: Obras Completas. Madrid: Biblioteca Nueva, 1981. t. II, p. 1620-4.

(1912-3). Totem y tabu. In: Obras Completas. Madrid: Biblioteca Nueva, 1981. t. II, p. $1745-850$.

(1915). Los instintos e sus destinos. In: Obras Completas. Madrid: Biblioteca Nueva, 1981. t. II, p. 2039-52.

(1915-17). Lecciones introdutorias al psicoanálisis In: Obras Completas. Madrid: Biblioteca Nueva, 1981. t. II, p. 2225-34.

(1920). Mas allá del principio del placer. In: Obras Completas. Madrid: Biblioteca Nueva, 1981. t. III, p. 2507-41.

(1921). Psicología de las masas y analisis del yo. In: Obras Completas. Madrid: Biblioteca Nueva, 1981. t. III, p. 2563-610.

(1929[1930]). El malestar en la cultura. In: Obras Completas. Madrid: Biblioteca Nueva, 1981. t. III, p. 3017-67.

(1938[1940]). Compendio del psicoanálisis. In: Obras Completas. Madrid: Biblioteca Nueva, 1981. t. III, p. 3379-418.

(1924-8[1939]). Moisés y la religion monoteísta: tres ensayos. In: Obras Completas. Madrid: Biblioteca Nueva, 1981. t. III, p. 3241-326.

GirARD, René (1972). A violência e o sagrado. São Paulo: Universidade Estadual Paulista, 1990.

WaCQUANT, Loic. Os condenados da cidade. Rio de Janeiro: Revan/Fase, 1991.

\section{Resumos}

Este trabajo problematiza la dicotomía individuo/sociedad en el debate social y político contemporáneo, enfatizando el papel del Psicoanálisis en el mismo, así como 


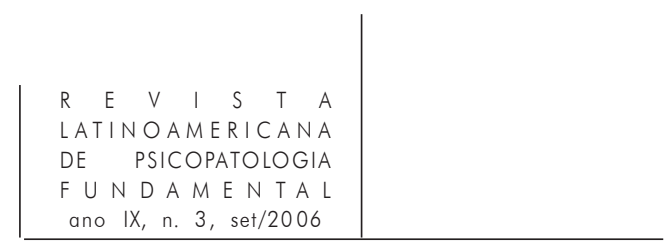

su creciente presencia en el pensamiento político de las últimas décadas. Se da destaque al diálogo entre el pensamiento social contemporáneo y el pensamiento freudiano en la reformulación de cuestiones epistemológicas centrales que giran en torno del tema individuo/sociedade, y señala algunos avances posibles de ese trabajo de discusión sobre ambivalencia.

Palabras claves: Psicoanálisis, política, individuo, sociedad, ambivalencia

Ce travail problematise la dichotomie individu/société dans le débat social et politique contemporains, soulignant le rôle de la psychanalyse dans ce débat, et sa présence de plus en plus importante dans la pensée politique des ces dernières décénies. Il met en valeur le dialogue engagé entre la pensée sociale contemporaine et la pensée freudienne autour du remaniement des questions épistemologiques centrales sur le thème individu/ société, et signale quelques progrès possibles de cette entreprise, centrée sur la discussion sur l'ambivalence.

Mots clés: Psychanalyse, politique, individu, société, ambivalence

This article discusses the dichotomy between individual and society in the contemporary social and political debate. The role of psychoanalysis in this debate is also treated, as well as its increasing presence in political thought in recent decades. Attention is called to the dialog between contemporary social thought and Freudian thought, and how this dialog relocates several important epistemological questions concerning the individual vs. society. The article also discusses possible inroads for this venture based, on the discussion of ambivalence.

Key words: Psychoanalysis, politics, individual, society, ambivalence 